\title{
Relief of symptoms in palliative care and the bioethical implications: an integrative review
}

\begin{abstract}
Objective: To describe the content addressed in the Brazilian scientific productions on the topics of symptom relief in palliative care and the bioethical implications.

Method: Integrative review of literature in the databases BDENF, LILACS and MEDLINE, through the descriptors palliative care and bioethics, using complete texts and in Portuguese. We found 68 articles and of these, 17 publications were selected that met the inclusion criteria and established a consistent relationship with the theme.
\end{abstract}

Results: From the analysis of the publications, three categories were found; however, for this study, what the articles reported on the relief of symptoms in Palliative Care and its ethical implications were described.

Conclusion: As can be verified, the autonomy of the patient is referred to human dignity and in this sense, the search for the quality of the implementation of care for the human being in the finitude of life, should be based on ethical principles that value human relations, respect the patient's decisions and professional preparation in dealing with terminality.

Keywords: palliative care, death, ethic, bioethics
Volume 3 Issue 3 - 2019

\author{
Priscila Cristina da Silva Thiengo,' Pablo \\ Luiz Santos Couto, ${ }^{2}$ Antônio Marcos Tosoli \\ Gomes, ${ }^{3}$ Alba Nunes da Silva,' Glaudiston \\ Silva de Paula,' Samantha Souza da Costa \\ Pereira ${ }^{4}$ \\ 'Nurse, PhD student in Nursing, University of Rio de Janeiro, \\ Brazil \\ ${ }^{2}$ Nurse, Master in Nursing, Center for Higher Education of \\ Guanambi, Brazil \\ ${ }^{3}$ Nurse, Doctor of Nursing, University of Rio de Janeiro, Brazil \\ ${ }^{4}$ Nurse, Master of Public Health, Center for Higher Education of \\ Guanambi, Guanambi, Brazil
}

Correspondence: Pablo Luiz Santos Couto, Nurse, Master in Nursing/PPGENF-UFBA, Coordinator of the Nursing Collegiate-UniFG, UniFG, Teacher and UNEB, Brazil, Email pabloluizsc@hotmail.com

Received: August 17,2018 | Published: June 24, 2019

\section{Introduction}

The prolongation of life and illness has extended the conviviality of the patient, the family and the care team to the person in the terminal, who has to deal with the stress and the constant risk of collapse of the body. This has happened because of the technological development in the area of palliative care, perceptible from the moment the place of death moves from the houses to the hospitals, making it aseptic, distant, silent and often solitary, for company introduced in the body and the sound produced by the machines and the clock hand. ${ }^{1,2}$

The duration of the death process has also undergone significant changes, especially in the predominance of chronic diseases such as heart disease, cancer, neurological diseases and AIDS. ${ }^{3}$ Thus, the health team adopts innovative procedures such as the meaning and the hope that govern care in order to postpone death, which have stimulated debates in the area of ethics and bioethics. ${ }^{4}$

Thus, with the advancement of debates and studies in the field of bioethics, the theme of Palliative Care (CP) emerges, which are systematized and based on the provision of care aimed at guaranteeing a dignified death, or the so-called 'good death'. Planning is aimed at controlling physical and psychic symptoms. Thus, it values existential interests and social relations, paying attention to death without suffering and without loss of dignity, promoting the reflection of a new paradigm that broadens the understanding about the human body, sickness and death. ${ }^{3-5}$

Thus, when considering health care based on human relations and palliative care as a relevant topic for discussion and reflection, it aims to describe the content addressed in the Brazilian scientific productions on the issues of relief of symptoms in palliative care and bioethical implications.

\section{Method}

This is an integrative literature review, focused on the study of palliative care and bioethics. For this purpose, the method of integrative literature review was used, which allows the search, critical evaluation and synthesis of the available evidence of the investigated subject, and its final product is the current state of knowledge of the subject investigated. ${ }^{6}$

For this study, it was defined as a guiding question: "Which bioethical aspects aimed at the relief of symptoms in palliative care are addressed by nursing articles published in scientific journals between the years 2011 and 2016?". Descriptors: "palliative care" and "bioethics" were used as descriptors. The search was performed in May 2017, in the Virtual Health Library Portal (VHL), in the following databases: Nursing Database (BDENF), Latin American and Caribbean Literature in Health Sciences (LILACS) and the Online Medical Literature Search and Analysis System (MEDLINE). We selected articles published only in Portuguese, with full text available online and in Brazilian scientific journals. The following publications were excluded from the analysis: Letters to the Editor, Editorials, reviews or reflection and the complete texts that did not address the theme. For articles that appeared in more than one database, only one was used to be submitted for analysis in order to avoid duplicity of articles.

For the data collection, an instrument was used, constructed by the authors, containing the following variables: year of publication, author, title and main results. We identified 68 articles in the databases and from the careful reading of titles and abstracts, we selected those that met the following criteria: a. Published between 2011 and 2016; B. Full version of the study available online; w. They related the search descriptors in the abstract and in the text. Of the articles identified, 50 were excluded because they did not meet the established criteria: they did not present answers to the research question and the objective proposed for this study (28), they were in another language (17) and were repeated (6). Finally, the corpus of the review was composed of 17 articles, organized in a synoptic table that facilitates the visualization, analysis and synthesis of articles that met the preestablished criteria. 
For the analysis of the results, a priori, was carried out a floating reading and then a critical reading of the selected material for classification of text units and construction of inferences and interpretations. Subsequently, thematic, descriptive and qualitative analysis was carried out, which allowed the identification of similarities and divergences in interpreted results.

\section{Results}

After the collection of the 17 articles, they were read in full and a data collection form was used to facilitate the analysis and later the preparation of the review (Table 1).

Table 1: Synthesis of the results of the studies included in the literature review, according to publication data between the years 2011 to 2016.

The following will be presented the discussion of the results of one of the thematic categories raised by the study, entitled: the relief of symptoms in palliative care and its bioethical implications.

Table I Summary of the results of the studies included in the literature review, according to publication data from 20 I I to 20 I6.

\section{Synthesis of the results of the analyzed studies}

The results indicate that a humanized care assumes, among many aspects, the prudent use of palliative sedation as an available resource for the minimization of suffering in the process of dying. ${ }^{6}$

It can be verified that there are few studies related bioethics and palliative care (PC), proven by the scarce literature on the subject. PC professionals seek the good of this human being, often not using all the technology available to continue a futile treatment. ${ }^{7}$

The results showed that the research participants recognize the importance of Bioethics principles in the care of patients with HIV / AIDS under PC. 8

We highlight the dimensions of the sense of responsibility, the influence of moral conscience in decisions, the deliberation of protecting the other at risk and the experience of professional overcoming episodes. ${ }^{9}$

Educational measures related to the dying process should be encouraged during medical training, developing dialogue and recognition of the other as a moral agent. Bioethics can help in the critical development of these professionals, helping to resolve the ethical conflicts that arise not only in the process of limiting life support, but in other areas of medicine. ${ }^{10}$

Dialogue with parents is the procedure that legitimizes the medical initiative to propose therapeutic limitation. In conclusion, severe cerebral malformations result in a context of terminality of life, in which limitation to respiratory support is the main conflict faced and to which bioethical principles of PC."

It is concluded that, although nurses understand the three concepts of terminality and recognize their importance in relation to care, it was not possible to infer from the responses analyzed that in their daily practice the principles of ortho-thasia are effectively present, which can negatively influence the quality of care. ${ }^{2}$

The main ethical issues identified were: respect for patient autonomy; veracity and right to information; communication skills; siege of silence; participation in the deliberation process; choice of place of treatment and death. ${ }^{13}$

This topic is not well explored in the national scenario by nursing researchers. The studies found were not just about euthanasia alone, but about end-of-life and palliative care, dysthanasia, orthothanasia, and spoke of other actors involved in the decision-making process at the end of life. ${ }^{15}$

The autonomy of the patient with him and the specificities of the hospital environment in PC is very important and the psychologist plays a fundamental role in this purpose, when seeking strategies to help in the confrontation and elaboration of the emotional and intense experiences experienced in the finite phase of life, with the patient, the family and also the health team. ${ }^{16}$

In the evaluation of Moral-Psychological Development, the patients demonstrated that they were able to make decisions in their best interest and they were satisfied with the capacity to establish social, personal and intimate relationships, even when they were hospitalized. ${ }^{20}$

The position of the physicians in relation to the PC is fragmented, involving some difficulties regarding the termination of life, especially regarding the clarifications and the patients' options. ${ }^{21}$

The ethical problems detected were: scarcity of resources; ignorance about PC; lack of communication skills; difficulty in establishing limits in clinical relation; work overload; lack of support from referral services. ${ }^{23}$

It is concluded that, although a good part of the interviewees had little understanding on the subject "vital testament", the great majority stood in favor of its acceptance. ${ }^{24}$

It concludes that the reflection about the terminality has been increasing, but still is insufficient with respect to the practice of the nursing professionals. It is noticed that the difficulty in dealing with death is a problem common to health professionals. ${ }^{25}$

It is concluded that it is necessary to include in the medical training the discussion and the study on approach and coping with death, in order to minimize ethical dilemmas experienced by professionals in their daily practice. ${ }^{26}$

It is concluded that the narrative bioethics applied to the CP can offer important subsidies to elucidate the questions related to the understanding of the spiritual sphere, by providing analytical frameworks for the human being that expresses, feels, says and makes sense in what is said. ${ }^{28}$ 


\section{Discussion}

The relief of symptoms in palliative care and its bioethical implications. The studies mentioned here expose the discussion about the care and use of certain technologies necessary for the implementation of palliative care, where bioethical issues related to their use are discussed. It is known that palliative care aims to relieve uncomfortable symptoms to the end-of-life patient, whose purpose is to provide quality of life. However, the quest for the well-being of the other as an essential action of care involves ethical issues to be weighed.

The debate on the use of drugs to ensure the fight against infections and to minimize pain in patients in the final stage of life has been highlighted in two studies. ${ }^{6,7}$ Some professionals assure that there is no consensus on this, however, it defends its use in order to minimize suffering and discomfort. ${ }^{4,7}$ Other studies also demonstrate the difficulty of deciding whether to settle for palliative sedation ${ }^{8,9}$ and issues related to the feeding of terminally ill patients6, ratifying the need for multiprofessional team reflection on the patient's relatives about the problems and ethical conflicts generated. ${ }^{9}$

For prudent and responsible decisions to be deliberate, it is necessary that the facts involving illness and terminality be clarified, both to the patient and to his relatives, and the possible ethical conflicts of professionals are considered so that the desire of the patient is respected..$^{10-12}$ There is also a recommendation that the right to information and respect for the autonomy of the patient in relation to decision-making should be guaranteed. ${ }^{13}$

As regards the principles of beneficence and non-maleficence, it should be taken into account that the therapeutic decision whether or not to start treatment should be taken together with the terminal person and his family, from the point of view of palliative care. ${ }^{11-13}$ This is a discussion that mixes technical aspects and ethical questions, and must aggregate the value of the human dignity of the patient. Therefore, it is necessary to think collectively, listening to the health professionals involved, the family and the patient himself so that he does not enter the field of excessive medicalization and, consequently, in the therapeutic obstinacy. ${ }^{7-14}$

Respect for the principle of autonomy and beneficence makes it possible to offer benefits to the patient by promoting care in a perspective that meets their physical, psychosocial and spiritual needs. Thus, it becomes evident that the practice of comprehensive care is the guiding principle of health care and that it extrapolates the technique of care. ${ }^{15,16}$

The communication must be guided by truth and frank dialogue is pointed out as a necessary component for the therapeutic relationship, being an elementary condition for the patient to exercise autonomy and the application of the principle of beneficence. However, it should be recognized the emotional limits of the patient in relation to what will be exposed, therefore, professionals need to develop communication skills. ${ }^{6,14-18}$

In the area of palliative care, despite the importance of talking about death with patients and family, many report that they only had this type of conversation when an opportunity came from the patient.The lack of communication by the professional was justified by consuming too much time and by them consider that the discussion is not beneficial for the patients, because it is stressful and uncomfortable $e^{9,14-16}$

For this reason, the adequate understanding of the palliative care provided to the human being in terminality is the primary point of treatment, so that, regardless of life expectancy, the best care is given to the patient. ${ }^{19,20}$ However, health professionals are faced with the dying process, with pain and grief, often are not prepared to deal with this phenomenon, and sometimes do not know how to talk about the situation in which the patient is, both to this and to the family. ${ }^{21-25}$

Before that, several studies ${ }^{6,7,13}$ propose the insertion of the concepts of bioethics still in the undergraduate program to help health professionals to better face the ethical dilemmas involved in palliative care, death and human suffering. The health care model, taught in undergraduate health professions in Brazil, is based on prevention, diagnosis, effective treatment and cure of diseases. ${ }^{23-26}$ This saving assistance model, when caring with the finitude of the other, gives rise to feelings of impotence, insecurity and unpreparedness in the face of death. ${ }^{27,28}$

\section{Conclusion}

We conclude the need to approach bioethics in the care of the human being in terminality, especially when it comes to palliative care. This is put before the autonomy of the patient, which refers to human dignity and in this sense, the search for the quality of relationships, also addresses the respect of their decisions and the preparation of the professional to deal with the finitude of life.

Both autonomy and beneficence were dealt with in depth in the articles, revealing how their favoring can minimize the pain and suffering of these patients by respecting their decisions, or by the family when it is unable to decide the best course of action. Nonmaleficence was also associated with the principle of beneficence, associated with the search for the good of the human being, which means, often, not to use all the technology to give continuity to a treatment that prolongs suffering, seeking to protect it possible damage.

The studies suggest the need to introduce concepts of bioethics to undergraduates and that they be incorporated into health practices from the beginning of the course. It is imperative that future professionals have spaces for reflection, which consider ethics in the care and appreciation of interpersonal relationships, in order to guarantee greater comfort possible to people in terminal situation.

\section{Acknowledgments}

None.

\section{Conflicts of interest}

The authors declare there is no conflict of interest.

\section{References}

1. Kovács MJ. Health institutions and death: from no communication. Psicol Ciênc Prof. 2011;31(3):482-503.

2. Esslinger I. Whose life is it, anyway? Discovering death scenarios in the hospital. São Paulo: Casa do Psicólogo; 2004.

3. Schramm FR. Finitude and Bioethics of the End of Life. Rev bras cancerologia. 2012;58(1):73-78.

4. Paiva FCL, Almeida Júnior JJ, Damásio AC. Ethics in palliative care: conceptions about the end of life. Rev bioét (Impr). 2014;22(3):550-560.

5. Eich M, Verdi MIM, Martins PPS. Moral resolution in palliative sedation for a team of oncologic palliative care. Rev bioét (Impr). 2015;23(3):583592. 
6. Mendes KDS, Silveira RCCP, Galvão CM. Integrative review: Research method for incorporating evidence into health and nursing. Texto \& contexto enferm. 2008;17(4):758-764.

7. Crippa A, Lufiego CAF, Feijó AGS, et al. Bioethical aspects in the publications on palliative care in the elderly: critical analysis. Rev bioét. 2015;23(1):149-160.

8. Vasconcelos MF, Costa SFG, Lopes MEL, et al. Palliative care in HIV/ AIDS patients: principles of bioethics adopted by nurses. Ciênc saúde coletiva. 2013;18(9):2559-2566.

9. Nunes L. Ethical problems identified by nurses in relation to users in critical situation. Rev bioét. 2015;23(1):187-199.

10. Paranhos GK, Rego S. Paediatric life support limitation: ethical arguments. Rev bioét. 2014; 22(3):519-528.

11. Palhares D, Santos IA, Cunha ACR. Therapeutic limitation for children with severe brain malformations. Rev bioét. 2016;24(3):567-578.

12. Silva RS, Evangelista CLS, Santos RD, et al. Perception of intensive nurses in regional hospital on distanasia, euthanasia and Orthothanasia. Rev bioét. 2016;24(3):579-589.

13. Abreu CBB, Fortes PAC. Ethical issues regarding patient preferences in palliative care. Rev bioét. 2014;22(2):299-308.

14. Wilson $\mathrm{F}$, Ingleton $\mathrm{C}$, Gott $\mathrm{M}$, et al. Autonomy and choice in palliative care: time for a new model? J Advanc Nursing. 2014;70(5):1020-1029.

15. Santo CCE, Lima CFM, Silva LA, et al. Scientific production of nursing about euthanasia: an integrative literature review. $J$ res fundam care. 2013;6(3):1231-1242.

16. Rodriguea LA, Cazeta FL, Ligeiro F. Patient autonomy in palliative care and psychologist intervention: a bioethical look. CuidArte enferm. 2015;9(2):131-141.

17. Ferreira APQ, Lopes LQFE, Melo MCB. The role of the psychologist in the palliative care team with the cancer patient. Rev SBPH. 2011;14(2):8598
18. Baldessin A. Dying well equipped. Medicina Ribeirão Preto. 2005;38(1):55-59.

19. Bettinelli LA, Pomatti DM, Brock J. Invasion of privacy in ICU patients: perceptions of professionals. Bioethikos. 2010;15(4):44-50.

20. Wittmann-Vieira R, Goldim JR. Bioethics and palliative care: decision making and quality of life. Acta Paul Enferm. 2012;25(3):334-339.

21. Oliveira FT, Flávio DA, Marengo MO, et al. Bioethics and humanization in the final phase of life: physicians' vision. Rev bioét (Impr). 2011;19(1):247-258.

22. Guimarães MM, Carvalho MAF, Simões IAR, et al. Euthanasia and distanásia: perception of doctors and nurses of a southern city of Minas Gerais. Rev enferm UERJ. 2016;24(2):e9545.

23. Saito DYT, Zoboli ELCP. Palliative care and primary health care: scoping review. Rev bioét (Impr). 2015;23(3):593-607.

24. Silva JAC, Souza LEA, Costa JLF, et al. Knowledge of medical students regarding lining wills. Rev bioét (Impr). 2015;23(3):563-571.

25. Santana JCB, Santos AV, Silva BR, et al. Nursing and terminality teachers in dignified conditions. Rev bioét (Impr). 2013;21(2):298-307.

26. Poletto S, Bettinelli LA, Santin JR. Death experiences of elderly patients in medical practice and human dignity. Rev bioét (Impr). 2016;24(3):590-595.

27. Gomes GC, Xavier DM, Mota MS, et al. Giving difficult news to the child's family in serious situation or in terminality process. Rev-enferm UERJ. 2014;22(3):347-352.

28. Manchola C, Brazão E, Pulschen A, et al. Palliative care, narrative spirituality and bioethics in specialized health care unit. Rev bioét (Impr). 2016;24(1):165-175. 